\title{
Presenilin/ $\gamma$-secretase and inflammation
}

\author{
Carlos A. Saura*
}

Institut de Neurociències, Departament Bioquímica i Biologia Molecular, Centro de Investigación Biomédica en Red Enfermedades Neurodegenerativas (CIBERNED), Universitat Autònoma de Barcelona, Bellaterra, Spain

\section{Edited by:}

Elena Galea, Universitat Autònoma de

Barcelona, Spain

\section{Reviewed by:}

Magdalena Sastre, Imperial College London, UK

Elena Galea, Universitat Autònoma de Barcelona, Spain

\section{${ }^{*}$ Correspondence:}

Carlos A. Saura, Institut de

Neurociències, Departament de Bioquímica i Biologia Molecular. Facultat Medicina, M2-113, Universitat Autònoma de Barcelona, Bellaterra

(Barcelona) 08193, Spain.

e-mail:carlos.saura@uab.es
Presenilins (PS) are the catalytic components of $\gamma$-secretase, an aspartyl protease that regulates through proteolytic processing the function of multiple signaling proteins. Specially relevant is the $\gamma$-secretase-dependent cleavage of the $\beta$-amyloid precursor protein (APP) since generates the $\beta$-amyloid (A $\beta$ ) peptides that aggregate and accumulate in the brain of Alzheimer's disease (AD) patients. Abnormal processing and/or accumulation of $A \beta$ disrupt synaptic and metabolic processes leading to neuron dysfunction and neurodegeneration. Studies in presenilin conditional knockout mice have revealed that presenilin-1 is essential for age-dependent $A \beta$ accumulation and inflammation. By contrast, mutations in the presenilin genes responsible for early onset familial $A D$ cause rapid disease progression and accentuate clinical and pathological features including inflammation. In addition, a number of loss of function mutations in presenilin-1 have been recently associated to non-Alzheimer's dementias including frontotemporal dementia and dementia with Lewy bodies. In agreement, total loss of presenilin function in the brain results in striking neurodegeneration and inflammation, which includes activation of glial cells and induction of proinflammatory genes, besides altered inflammatory responses in the periphery. Interestingly, some non-steroidal anti-inflammatory drugs that slow cognitive decline and reduce the risk of $A D$, decrease amyloidogenic $A \beta 42$ levels by modulating allosterically PS/ $\gamma-$ secretase. In this review, I present current evidence supporting a role of presenilin $\gamma$-secretase signaling on gliogenesis and gliosis in normal and pathological conditions. Understanding the cellular mechanisms regulated by presenilin/ $\gamma$-secretase during chronic inflammatory processes may provide new approaches for the development of effective therapeutic strategies for AD.

Keywords: neuroinflammation, Alzheimer's disease, neurodegeneration, frontotemporal dementia, amyloid, Notch, NSAID

\section{INTRODUCTION}

Inflammation is the main biological defense mechanism in response to external injury. Besides having multiple therapeutical benefits, inflammation has been extensively implicated in many pathological conditions including cancer, diabetes, heart infarct and brain diseases. Inflammatory responses are common in acute and chronic diseases of the central nervous system. For instance, inappropriate inflammation contributes directly to acute neurodegeneration during brain stroke, trauma and viral infection (Allan and Rothwell, 2003). Similarly, chronic inflammatory responses are also common to many age-related neurodegenerative disorders including Alzheimer's disease (AD). Neuroinflammatory responses, characterized by activation of glial cells, especially microglia and astrocytes, and increased production of inflammatory molecules are closely associated to neuropathological lesions in $\mathrm{AD}$ brain (Mrak and Griffin, 2005). Moreover, inflammation is an important neuropathological feature that contributes to neuronal dysfunction and cognitive dysfunction during normal aging and age-related neurodegenerative conditions (Lynch, 2010).

$\mathrm{AD}$ is the most common neurodegenerative disorder in the elderly. $\mathrm{AD}$ causes progressive cognitive impairment and behavioral disturbances leading finally to dementia. The classical neuropathological features of $\mathrm{AD}$ brain include neuronal loss and the presence of extracellular amyloid plaques containing $\beta$-amyloid
$(A \beta)$ peptides and intraneuronal neurofibrillary tangles (NFTs) composed of aggregated phosphorylated tau. $A \beta$ peptides, the principal constituents of amyloid plaques, stimulate glial cells to undergo morphological and gene expression changes causing activation and/or secretion of proinflammatory molecules including cytokines, complement components, adhesion molecules and cyclooxygenase (COX) enzymes (Mrak and Griffin, 2005). Once activated, microglia and astrocytes contribute to removal of $A \beta$ from the brain parenchyma (Wyss-Coray et al., 2001, 2003). By contrast, long-term chronic inflammatory responses contribute actively to neuron dysfunction and further neurodegeneration in $\mathrm{AD}$, which suggests that inflammation may have early benefits as well as long-term detrimental effects during progression of the disease.

The prevalent hypothesis of $\mathrm{AD}$ postulates that one of the initiating events of the disease is related to abnormal processing, aggregation and/or clearance of $\mathrm{A} \beta$ peptides (Hardy and Selkoe, 2002). The initial accumulation of $A \beta$ peptides and/or phosphorylated tau may occur when individuals are still cognitively normal, whereas accumulation of $A \beta$ in plaques and the presence of NFTs accompanied by neuronal dysfunction and neurodegeneration correlate closely with severity of clinical symptoms (Jack et al., 2010). At initial stages, accumulation of aggregated oligomeric $A \beta$ species can interfere with neuronal and 
synaptic function without affecting neuronal viability. The key step regulating $A \beta$ generation is the sequential proteolytic processing of amyloid precursor protein (APP) by $\beta$-secretase (BACE) and $\gamma$-secretase proteases. Presenilins (PS), the catalytic components of $\gamma$-secretase, are essential for $A \beta$ generation, age-dependent $A \beta$ accumulation and inflammatory responses during progression of the disease (Saura et al., 2005). Therefore, modulation of $\gamma$-secretase by using specific inhibitors has been suggested as potential therapeutic strategy to reduce $A \beta$-induced pathology and clinical symptoms. Interestingly, some non-steroidal anti-inflammatory drugs (NSAIDs) that ameliorate symptoms and reduce the risk of $\mathrm{AD}$ were shown to lower the generation of $\mathrm{A} \beta 42$ by affecting the $\gamma$-secretase-dependent cleavage of APP (Weggen et al., 2007). The therapeutic benefits of $\mathrm{PS} / \gamma$-secretase inactivation may directly depend on the target selectivity and reduction of side effects on other important signaling pathways.

Here, I describe recent findings implicating PS $/ \gamma$-secretase on inflammation, especially those related with cellular and genetic mechanisms regulated by PS during inflammatory responses in brain diseases. Finally, I discuss implications for development and ongoing therapeutic strategies based on $\gamma$-secretase targeting and modulation in $\mathrm{AD}$.

\section{PRESENILIN BIOLOGY}

PS are multifunctional proteins that contain the catalytic core of $\gamma$-secretase, an aspartyl protease that mediates the regulated intramembrane cleavage of multiple cell surface signaling proteins including among others APP, Notch receptors, ErbB4, Eand N-cadherins, p75 and EphB2 (Koo and Kopan, 2004). PS are transmembrane proteins that undergo regulated endoproteolysis to generate $\mathrm{N}$ - and C-terminal fragments, which are the predominant PS species that accumulate in vivo within the enzymatic complex (Thinakaran et al., 1996; Saura et al., 1999). The functional active $\gamma$-secretase complex is composed of PS dimers and other components such as nicastrin, Pen-2 and Aph1 (De Strooper, 2003; Cervantes et al., 2004). These four components are essential for stabilization and function of $\gamma$-secretase. The mechanism of complex assembly involves stabilization of full-length presenilin by Aph-1/nicastrin, followed by binding of Pen-2, which facilitates endoproteolysis of presenilin and confers the $\gamma$-secretase activity (Takasugi et al., 2003).

Two presenilin homologous presenilin-1 (PS1) and presenilin-2 (PS2) located on chromosomes 14q24.3 and 1q31-q42, respectively, are present in mammals. Gene expression studies in different species have revealed wide-spread expression of PS in different cell types and tissues. PS1 and PS2 are ubiquitously expressed in most tissues including the brain (Lee et al., 1996; Lah et al., 1997). During mouse development, PS1 mRNA expression is particularly high in neural organs, whereas PS2 is barely expressed. By contrast, PS1 and PS2 mRNAs are highly expressed in neurons of the hippocampus and entorhinal cortex in adult mouse brain (Lee et al., 1996). In human brain, PS1 protein is highly expressed in pyramidal neurons of the hippocampus and neocortex, magnocellular neurons of the basal forebrain, brainstem motoneurons and some interneuron populations (Kim et al., 1997; Lah et al., 1997). Although PS are mainly expressed in neurons, PS1 and PS2 mRNAs are detected at low levels in white matter glial cells and cultured astrocytes (Lee et al., 1996). However, PS1 expression is upregulated in reactive astrocytes and activated microglia under pathological conditions such as those occurring in $\mathrm{AD}$, brain injury and hypoxia (Weggen et al., 1998; Peers et al., 2004; Nadler et al., 2008).

\section{ROLE OF PRESENILINS ON GLIOGENESIS}

$\gamma$-Secretase facilitates Notch signaling by mediating the ligandinduced proteolytic cleavage of Notch1 receptor that generates the Notch intracellular domain (NICD) (De Strooper et al., 1999). NICD then translocates to the nucleus where binds to CBF1/RBPJ $k$ / $\mathrm{Su}(\mathrm{H}) / \operatorname{Lag} 1$ (CSL) family of transcriptional activators or repressors that participate in the transcriptional control of downstream target genes. The function of the Notch signaling pathway is specially relevant for controlling cell fate decisions during development. Notch signaling mediates neural stem cell survival, self-renewal, proliferation and cell fate specification during central nervous system development (Lathia et al., 2008). In this way, Notch signaling maintains neural progenitor cells in a proliferative stage, inhibits neuronal differentiation and specifies radial glial cell fate (Gaiano and Fishell, 2002). Activation of Notch- 1 and Notch-3 in embryonic progenitors promotes radial glial fate and astrocyte fate postnatally (Gaiano et al., 2000). Accordingly, PS1-deficient mice show disturbed neurogenesis and somite formation, premature differentiation of progenitor cells accompanied by severe brain morphological defects resembling Notch mutants (Handler et al., 2000). Therefore, PS/ $\gamma$ secretase-dependent Notch signaling promotes glial and astrocytic fates in the developing and adult brain (Figure 1).

By contrast, $\mathrm{PS} / \gamma$-secretase represses the astrocytic fate of embryonic neural precursors in the developing brain by regulating the activation of the tyrosine kinase receptor ErbB4. Similarly to Notch processing, upon neuregulin binding and activation of ErbB4, $\gamma$-secretase releases the intracellular domain of ErbB4 (Ni et al., 2001), which then binds to TAB2 and the corepressor N-CoR (Sardi et al., 2006). This complex translocates to the nucleus and represses expression of astrocytic genes required for astrocyte fate, an observation that agrees with accelerated astrogenesis observed in ErbB4 knockout mice (Sardi et al., 2006). Thus, PS/ $\gamma$-secretase-dependent nuclear signaling and gene transcription by ErbB4 directly regulates glial fate specification (Figure 1).

\section{PRESENILIN $/ \gamma$-SECRETASE IN ALZHEIMER'S DISEASE AND FRONTOTEMPORAL DEMENTIA}

$\gamma$-Secretase plays a critical role on $\mathrm{AD}$ pathogenesis by mediating the generation of $A \beta$ peptides. $A \beta$ generation results from the extracellular cleavage of APP by BACE1 and after shedding of the soluble ectodomain (APPs $\beta$ ), $\mathrm{PS} / \gamma$-secretase cleaves the transmembrane domain of the APP C-terminal fragment to generate A $\beta$ peptides of variable length (39-43 aa) (Selkoe, 2002). PS/ $\gamma$-secretase also cleaves APP on the $\varepsilon$-cleavage site to generate the APP intracellular domain (AICD), a cytosolic fragment that translocates to the nucleus, activates gene expression and regulates apoptotic cell death (Muller et al., 2008). Presenilin is essential for generation and accumulation of $A \beta$, as evidenced by the lack of $A \beta$ production in cells derived from PS1 and PS1/PS2 deficient mice (De Strooper et al., 1998; Zhang et al., 2000) and the absence of $A \beta$ accumulation and amyloid plaques in the brain of APP transgenic mice lacking PS1 expression (Saura et al., 2005) (Figure 2). 

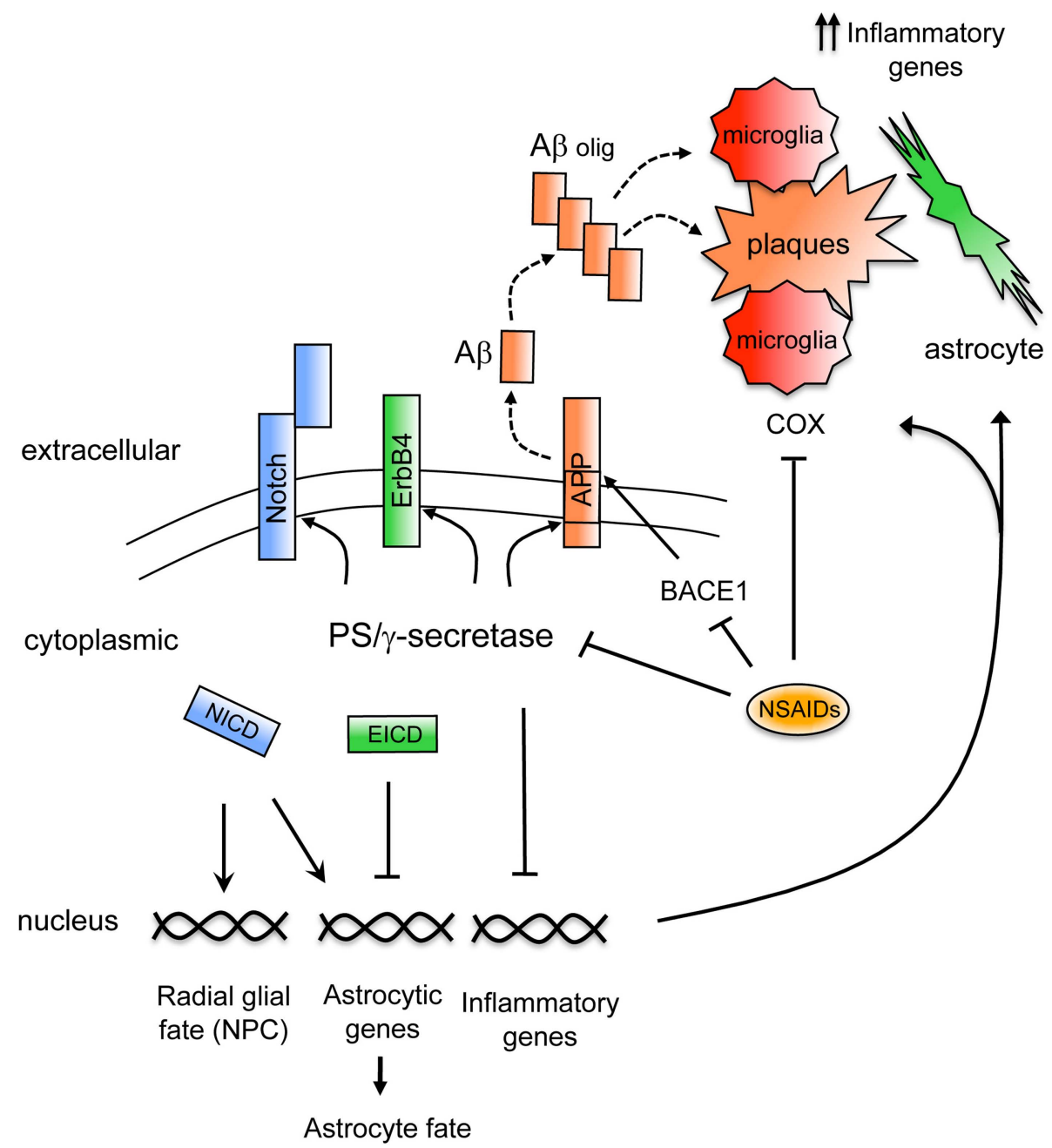

FIGURE 1 | Mechanisms regulating brain inflammation by PS/ $\boldsymbol{\gamma}$-secretase. Schematic model showing signaling mechanisms regulated by PS $/ \gamma$-secretase on inflammation. The $\gamma$-secretase-dependent cleavage of APP generates the $A \beta$ peptide that following oligomerization ( $A \beta$ olig) accumulates in plaques in $A D$ brain (dashed lines). A $\beta$ stimulates inflammatory cells that upon activation upregulate proinflammatory genes and secrete inflammatory molecules. Activated microglia and reactive astrocytes accumulate surrounding the amyloid plaques. Non-steroidal anti-inflammatory drugs (NSAIDs) reduce inflammation by acting through different molecular mechanisms including inhibition of COX enzymes in microglia or by reducing A 342 generation through $\gamma$-secretase or BACE1. On the other hand, the $\gamma$ secretase-dependent cleavage of Notch receptor generates the Notch intracellular domain (NICD), which promotes radial glial and astrocyte fates in neural precursor cells (NPC) by affecting target gene expression. By contrast, $\gamma$-secretase-dependent cleavage of ErbB4 generates the ErbB4 intracellular domain (EICD) that represses expression of astrocytic genes. In addition, PS downregulate the expression of inflammatory genes in glial cells by still unknown mechanisms.
The first evidence linking PS and AD came from the discovery that autosomal dominant mutations in the PSEN1 gene were responsible for early-onset familial AD (Sherrington et al., 1995). This was followed by the finding that inherited mutations in PSEN2 caused AD with variable penetrance and later onset (Levy-Lahad et al., 1995; Rogaev et al., 1995). A large number of mutations in PSEN1 ( 170) and PSEN2 (14) are currently known to cause the majority $(\sim 30-50 \%)$ of familial AD cases ${ }^{1}$ (http://www.molgen. ua.ac.be/ADMutations). Mutations in PS alter the cleavage of APP resulting in generation of distinct amyloidogenic $A \beta$ peptides. Thus, several mutations in distinct domains of PS1 (E $\Delta 9, \mathrm{~A} 79 \mathrm{~V}, \mathrm{I} 143 \mathrm{~T}$, L166P, A231V, L262F, L282V, G384A) or PS2 (N141I) decrease total $A \beta$ or $A \beta 40$ levels with little or unappreciable changes on the more amyloidogenic A $\beta 42$ species (Kumar-Singh et al., 2006; De Strooper, 2007). Other studies have demonstrated increased $\mathrm{A} \beta 42(43)$ peptides, and/or increased $A \beta 42 / \mathrm{A} \beta 40$ ratio in cells or transgenic mice expressing mutant PS1 or PS2 genes (Selkoe, 2002). The concentration balance of different $A \beta$ species seems to be important for aggregation and their toxic effects in $\mathrm{AD}$ brain. Notably, the age of onset of dementia in families with PS mutations correlates with increase of $A \beta 42 / A \beta$ ratio and decrease $A \beta 40$ levels (Kumar-Singh et al., 2006). The fact that PS pathogenic mutations suppress the $\gamma$ - and/or $\varepsilon$-secretase cleavage of several substrates including APP has lead to the hypothesis that these mutations may act through a loss of function mechanism (De Strooper, 2007; Shen and Kelleher III, 2007). 


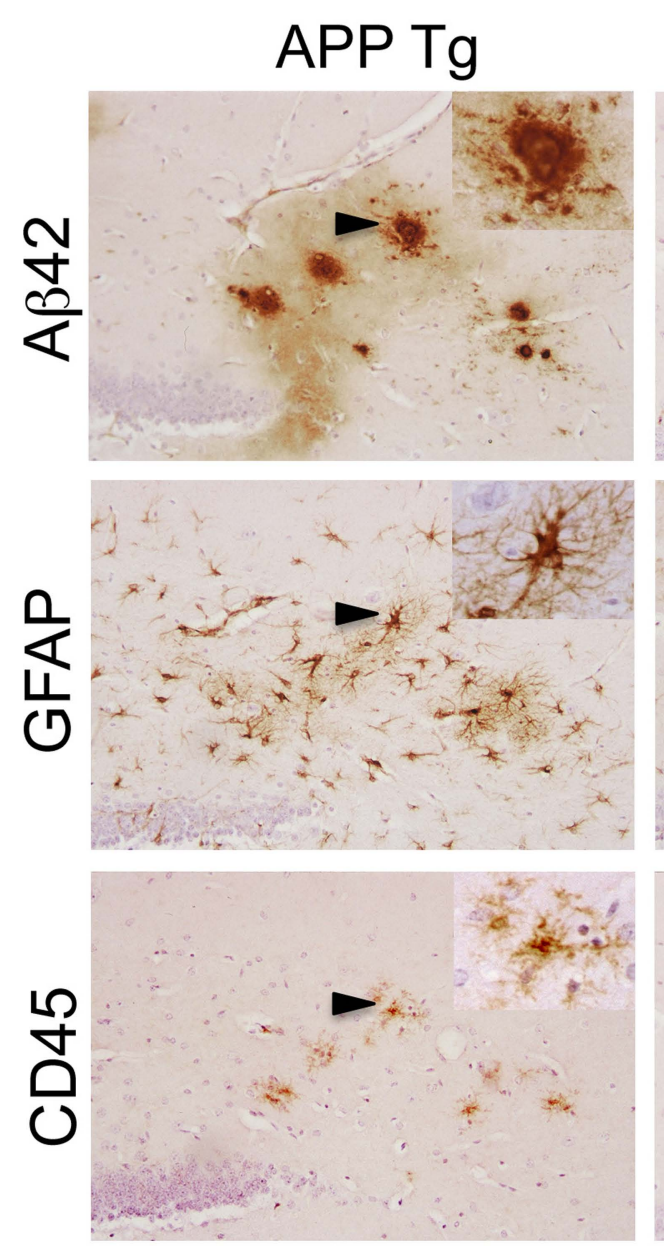

\section{PS1cKO;APP Tg}
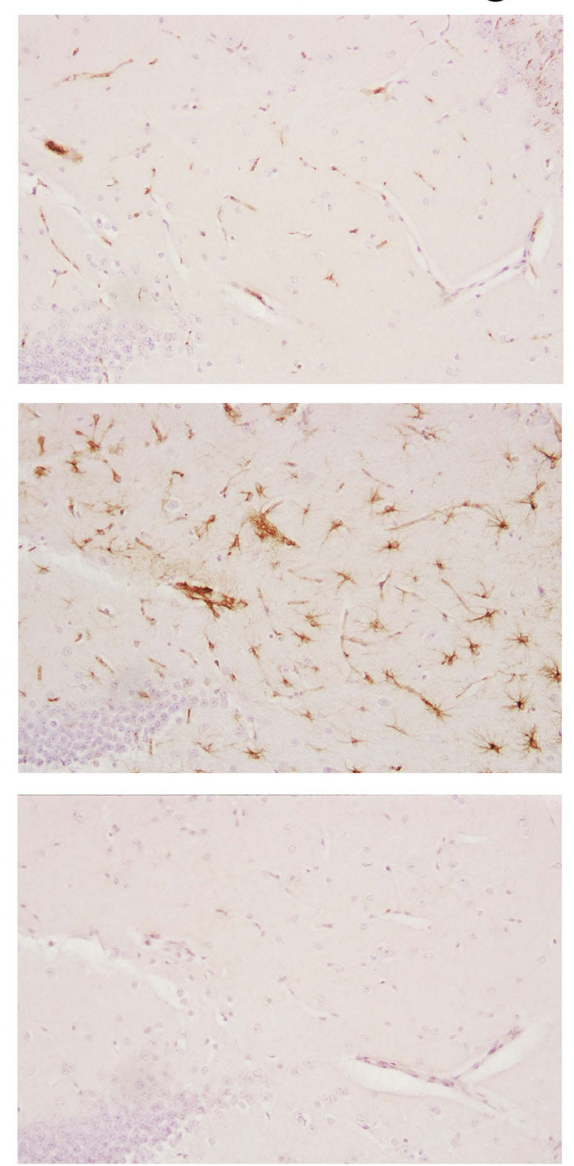

FIGURE 2 | PS1 inactivation reduces brain inflammation in APP transgenic mice. The images show consecutive serial brain sections of 6 month-old APP (APP swindi J20) and PS1cKO;APP transgenic (Tg) mice stained with antibodies against $A \beta 42$, GFAP and CD45. Reactive astrocytes labeled with a GFAP antibody and activated microglia stained with
anti-CD45 are found in the hippocampus of APP mice, but not in PS1cKO;APP mice. Activated microglia and astrocytes in APP brains are closely associated with $A \beta 42$-containing plaques as observed in these three consecutive brain sections. Insets: Higher-power views of the lesions marked with arrowheads.
Mutations in the presenilin genes accelerate age of onset and cause earlier and severe progression of neurodegeneration than sporadic AD. The presence of some PS mutations results in quantitative differences in brain neuropathology compared to sporadic forms of AD (Shepherd et al., 2009). Thus, despite similar disease duration, familial cases show similar or greater atrophy and neuronal loss, specially in the medial temporal lobes and frontal/temporal cortices, than sporadic AD cases (Gomez-Isla et al., 1999; Gregory et al., 2006; Shepherd et al., 2007). Similarly, an increase of NFTs and higher NFT-associated neuritic pathology have been reported in PS-linked familial AD cases compared to sporadic AD (Gomez-Isla et al., 1999; Sudo et al. 2005; Woodhouse et al. 2009). Several studies have also shown increased overall amyloid plaques, especially those containing higher deposition of $A \beta 42$ in genetics forms of AD (Shepherd et al., 2009). By contrast, other reports show similar amyloid plaque deposition in PSEN1 and sporadic AD cases (Nochlin et al., 1993; Lippa et al., 1996). The distinct effect of PS mutations on disease progression may reflect a differential effect of PS mutations on $\mathrm{A} \beta$ processing, tau phosphorylation and other signaling pathways (GSK3 $\beta$, $\beta$-catenin, calsenilin, Notch, CREB, $\mathrm{E} / \mathrm{N}$-cadherin, etc...).

Genetic studies have identified PSEN1 mutations in families presenting clinical symptoms of frontotemporal dementia (FTD), atypical dementia with a FTD phenotype and dementia with Lewy bodies (Hutton, 2004). For instance, the PSEN1 L424H mutation causes FTD characterized by AD neuropathology, whereas the PSEN1 V272A mutation is associated with subcortical dementia with Lewy body pathology (Zekanowski et al., 2006; Gomez-Tortosa et al., 2010). Several mutations in PSEN1 including L113P, G183V, L226F and V412I have been found in early-onset familial FTD (Raux et al., 2000; Dermaut et al., 2004; Bernardi et al., 2009). These PSEN1 mutations cause severe neurodegeneration and dementia associated with accumulation of phosphorylated tau in the absence of A $\beta$ pathology in the frontal cortex. Thus, the G183V mutation increases the levels of phosphorylated tau without affecting A $\beta 2$ levels and deposition (Dermaut et al., 2004). Consistent with a role 
of PS on tau phosphorylation, overexpression of mutant PS1 in mice results in activation of GSK-3 $\beta$ and enhanced phosphorylation of tau (Dewachter et al., 2008). Interestingly, inactivation of both PS1 and PS2 in the adult mouse brain leads to increased phosphorylation of tau and age-dependent memory deficits and neurodegeneration (Saura et al., 2004). This raises the possibility that some PS pathogenic mutations may cause memory deficits and neurodegeneration by affecting tau phosphorylation and/or aggregation.

\section{PRESENILINS AND BRAIN INFLAMMATION}

Abundant inflammation correlates with the initial cognitive decline and severity of dementia in AD (Parachikova et al., 2007). Reactive glial cells, especially activated microglia and astrocytes, and increased production of inflammatory molecules are associated to neuritic plaques (Holmes et al., 2009). Activation of microglia is initiated by local binding of fibrillar $\mathrm{A} \beta$ to $\mathrm{Clq}$ receptors and a receptor complex formed by the $\beta$-class scavenger receptor CD36, the integrin-associated protein/CD47, and the $\alpha(6) \beta(1)$-integrin (Eikelenboom and Veerhuis, 1996; Bamberger et al., 2003). The subsequent activation of intracellular signaling pathways in microglia leads to the proinflammatory response. Microglia activation induces secretion of cytokines and other neuroinflammatory molecules that promote stimulation and activation of astrocytes around the plaques. Once activated, microglia and astrocytes contribute actively to removal of $A \beta$ from the brain parenchyma (Wyss-Coray et al., 2001, 2003), as revealed by accumulation of $A \beta 42$ peptides in astrocytes in AD brain (Nagele et al., 2003).

An increase of neuroinflammatory mediators resulting from enhanced amyloid pathology in familial AD or as a direct consequence of PS mutations may have detrimental consequences for neuronal function. Monocyte chemoattractant protein-1 (MCP1), interleukin-6 (IL-6) and interleukin-8 (IL-8) are increased by familial AD-linked PS mutations (Sokolova et al., 2009), and mutant PS1 enhances expression of microglial factors that promote differentiation of neural precursor cells into glial fibrillary acidic protein (GFAP)-positive cells (Choi et al., 2008). Production of inflammatory cytokines like IL-1 $\beta$, IL- 6 and TNF $\alpha$ by activated microglia, but also by reactive astrocytes, negatively impact on neuronal function and behavior. For instance, secretion of toxic neuroinflammatory mediators such as reactive oxygen species (ROS), cytokines and chemokines directly contributes to neurite retraction, neuronal dysfunction and neuronal death in AD (Munch et al., 2003; Sokolova et al., 2009). Nonetheless, inflammatory cytokines have been suggested to be the primary contributors to synaptic plasticity deficits and behavioral changes during normal aging and age-dependent neurological diseases (Lynch, 2010). Recent findings demonstrate that overexpression of IL-1 $\beta$ in the hippocampus is accompanied by microglial activation and increased expression of chemokines MCP-1 and MIP-1, which negatively affect hippocampal-dependent memory (Moore et al., 2009). The negative impact of chronic inflammation on synaptic function during neurodegeneration has been corroborated in several studies in aged and AD transgenic mice (McGeer and McGeer, 2007).

Besides the classic neuritic plaques, cotton wool and inflammatory' plaques are specific pathological hallmarks commonly observed in familial AD caused by PS mutations. Cotton wool plaques, which are composed mainly of $A \beta 42$, are usually devoid of a compact amyloid core, neuritic changes and glial cell components (Mann et al., 2001). Cotton wool plaques are mainly detected in neocortex, limbic system and striatum in AD cases caused by PSEN1 mutations in exons 4, 5, 6, 8, 9 and 12 and intron 8 (Mann et al., 2001; Dumanchin et al., 2006), whereas they are very rare in lateonset AD (Le et al., 2001). By contrast, 'inflammatory plaques' are small dense plaques with a central core devoid of $A \beta$, phosphorylated tau, ApoE and $\alpha$-synuclein. 'Inflammatory plaques' display a strong inflammatory response in the form of numerous activated microglia and astrocytes in the cortex of familial AD cases linked to PSEN1 and APP mutations (Shepherd et al., 2005). The increase of inflammatory cells surrounding these plaques may contribute significantly to greater neuronal dysfunction and neurodegeneration in some genetic AD cases linked to PS mutations (Shepherd et al., 2009). The variability on clinical symptoms and brain pathology in subjects carrying the same PS1 mutation (Martikainen et al., 2009), suggests that other genetic, cellular or environmental factors may alter the pathological phenotypes in genetically predetermined familial AD cases.

\section{PRESENILINS AND BRAIN INJURY}

Epidemiological studies indicate that head trauma is an important risk factor for developing AD. Levels of PS1 and nicastrin increase significantly in activated astrocytes and microglia following brain damage by head injury, brain stabbing and inflammatory insult (Nadler et al., 2008). Indeed, chronic cortical gliosis and inflammatory mediators stimulate APP metabolism and elevate A $\beta$ peptides by increasing expression of APP and PS1, which in turn affects glial activation and neuronal function (Bates et al., 2002). Increased expression of mutant PS1 in astrocytes has been shown to contribute to astrocyte reactivity in response to ATP and glutamate through a mechanism involving increased $\mathrm{Ca}^{2+}$ oscillations (Johnston et al., 2006). This result indicates that PS1 mutations enhance intracellular $\mathrm{Ca}^{2+}$ mobilization in astrocytes contributing to the accelerated pathogenesis in familial AD. Similarly, PS1 expression increases in astrocytes under hypoxia conditions contributing to enhancement of intracellular calcium, whereas inhibition of PS1 reverses the effects of hypoxia on calcium signaling (Peers et al., 2004). Interestingly, hypoxia increases A $\beta$ levels by affecting APP processing and/or A $\beta$ clearance. The role of PS on brain hypoxia and its association to dementia is particularly intriguing since hypoxia, which can arise from cardiorespiratory diseases, predispose individuals to the development of dementias and especially to $\mathrm{AD}$ (Peers et al., 2009).

Brain ischemia is known to contribute to $\mathrm{AD}$ dementia, whereas individuals with severe cognitive decline and diagnosis of $\mathrm{AD}$ are at increased risk for ischemic events in the brain. PS $/ \gamma$-secretase seems to mediate the effect of Notch on ischemia events. In a mouse model of ischemic stroke, Notch increases the vulnerability of cells to undergo apoptosis, activates microglial cells and stimulates infiltration of proinflammatory leukocytes (Arumugam et al., 2006). By contrast, $\gamma$-secretase inhibitors and expression of a Notch 1 antisense reduce brain damage and improve neural function in that experimental model of ischemic stroke (Arumugam et al., 2006). Given that PS $\gamma$-secretase-mediated Notch signaling worsens brain damage during ischemic stroke, it has been suggested that agents that target Notch function may be useful for therapeutic interventions 
in some brain disorders (Lathia et al., 2008). These findings indicate that PS may contribute to brain damage and/or repair by regulating glial activation and function.

\section{PRESENILINS IN THE PERIPHERAL IMMUNE SYSTEM}

Enhanced cell death and calcium signaling defects in peripheral lymphocytes have been demonstrated in AD patients, suggesting that immune dysfunction can contribute to the pathogenesis of AD. Defects on T-cell activation by a PS1 mutation that causes familial $\mathrm{AD}$ has been reported in mutant PS knockin mice (Morgan et al., 2007). Lymphocytes from PS1 mutant transgenic mice show higher susceptibility to cell death as do peripheral cells from AD patients, which is likely caused by increased production of ROS and altered calcium levels (Eckert et al., 2001). Notably, lack of presenilins in the brain leads to robust inflammatory responses both in the brain and periphery. Beginning at 6 months of age, and coinciding with the neurodegenerative process, leukocytes and inflammatory mediators are elevated in serum of mutant PS1/PS2 conditional double knockout (PS cDKO) mice (Jiang et al., 2009). This finding indicates that inflammatory responses in the brain rapidly expand to systemic tissue under pathological conditions caused by loss of PS function in the brain.

Notch signaling plays a critical role on lymphocyte development by specifying $\mathrm{T}$ cell fate and differentiation. Notch signaling regulates CD4/CD8 $\mathrm{T}$ cell lineage commitment, whereas PS/ $\gamma$ secretase-dependent Notch signaling promotes the selection and maturation of CD4 and CD8 T cells in immature thymocytes (Laky and Fowlkes, 2008). A role of PS/ $\gamma$-secretase on T cell fate is evident in PS-deficient mice, in which lack of presenilin expression in thymocyte precursors inefficiently generate CD4+ T cells by impairing TCR signaling (Laky and Fowlkes, 2007). This has lead to the hypothesis that PS-dependent Notch signaling positively influences the selection and development of T cells by modifying TCR signaling. Similarly, inactivation of both PS in thymic cells results in a significant decrease of CD8+ $\mathrm{T}$ cells in the periphery (Maraver et al., 2007). However, whereas PS facilitate CD4+ $\mathrm{T}$ cell proliferation and cytokine secretion, they are not required for cytokine-induced Th1/Th2 fate selection (Ong et al., 2008). A direct role for PS proteins on B cell function has been also reported. Loss of PS function in B cells results in substantial deficit in both lipopolysaccharide and B cell antigen receptor-induced proliferation and signaling events, including a defect in anti-IgM-mediated calcium flux (Yagi et al., 2008).

A mechanism that could mediate presenilin-dependent regulation of lymphocyte activation is CD46, a signaling receptor with complement and $\mathrm{T}$ cell regulatory functions in human. In response to infectious pathogens such as Neisseria gonorrhoeae and Neisseria meningitidis, processing of CD 46 by PS/ $\gamma$-secretase stimulates CD46-dependent T cell responses (Weyand et al., 2010). Therefore, PS $/ \gamma$-secretase seems to be particularly important in response to pathogens by mediating the cleavage of CD46 and regulating signaling pathways in immune cells. Interestingly, PS1+/-; PS2-/- mice develop an autoimmune disease characterized by dermatitis, glomerulonephritis, keratitis and vasculitis. At advancing ages, these mutant mice develop skin hyperplasia, increased CD4+/CD8+ T cell ratio and B-cell infiltrates in several tissues (Tournoy et al., 2004). Together, compelling evidence suggests that PS $/ \gamma$-secretase regulates maturation of $\mathrm{T}$ cells, whereas its inactivation in the periphery has functional detrimental consequences for immune system.

\section{REGULATION OF INFLAMMATORY MECHANISMS BY PS}

A number of recent studies using PS loss-of-function mutant mice has added a new view on the role of PS on neuroinflammation. Consistent with the idea that PS1/ $\gamma$-secretase plays an essential role on $\mathrm{AD}$ pathogenesis, PS1 inactivation reduces significantly age-dependent $A \beta$ accumulation and amyloid plaque deposition in APP transgenic mice (Dewachter et al., 2002; Saura et al., 2005). Interestingly, conditional deletion of PS1 in the adult forebrain of APP transgenic mice reduces dramatically amyloid-associated microgliosis and astrocytosis (Figure 2), which is accompanied by reversal of hippocampal-dependent spatial and associative memory deficits (Saura et al., 2005). Whereas these results suggest that $\mathrm{PS} 1 / \gamma$-secretase is required for $\mathrm{A} \beta$-induced neuroinflammatory responses, they also indicate that targeting PS $1 / \gamma$-secretase may have therapeutic benefits in AD.

In contrast to the protective role of partial $\mathrm{PS} / \gamma$-secretase inactivation on amyloid pathology and inflammation, genetic ablation of both PS causes progressive inflammatory responses in the cerebral cortex of PS cDKO mice. The early widespread inflammatory response observed in PS CDKO mice is independent of $A \beta$ accumulation and appears before synapse loss and tau hyperphosphorylation (Beglopoulos et al., 2004). Inflammatory changes are the first pathological hallmarks observed in PS cDKO mice and these are followed by synaptic and memory impairments and progressive neurodegeneration (Saura et al., 2004). By 3 months of age, and long before activated inflammatory cells and neurodegeneration are apparent, several proinflammatory genes including complement component C1q $\alpha-\beta$, cathepsins D and S, small inducible cytokine A27, MHC histocompatibility proteins and $\mathrm{CD}$ antigens are up-regulated in the cortex and hippocampus of PS cDKO mice (Dong et al., 2007). Abundant reactive inflammatory cells, including activated microglia and reactive astrocytes, are observed in the hippocampus and neocortex of PS cDKO mutant mice by 6 months of age (Beglopoulos et al., 2004; Saura et al., 2004). Gene expression profile analyses in PS cDKO mice at that age have revealed an upregulation of multiple inflammatory genes including complement component C1q $\alpha-\beta$, MHC histocompatibility proteins, cathepsins $\mathrm{D}, \mathrm{H}, \mathrm{S}$ and $\mathrm{Z}$, chemokines, $\mathrm{CD}$ antigens and GFAP (Beglopoulos et al., 2004; Dong et al., 2007). Interestingly, the complement system, which targets toxic substances in the immune system, is directly involved in the inflammatory responses in $\mathrm{AD}$ and Down syndrome patients (Tenner, 2001). Cathepsin S, a lysosomal cysteine protease that is secreted by activated microglia and macrophages and mediates major histocompatibility class II-dependent immunity, is increased in AD and Down syndrome brains (Lemere et al., 1995). On the other hand, increased expression of GFAP, a marker of astrogliosis, correlates with progression of dementia and synaptic and tau pathologies in AD brain (Ingelsson et al., 2004).

Interestingly, cognitive stimulation by long-term environmental enrichment improved memory and reduced brain degeneration and astrogliosis in PS cDKO mice. Environmental enrichment significantly reduced 34 genes related to immunity and inflammation 
that were upregulated in the hippocampus of PS CDKO mice (Dong et al., 2007). These findings suggest that the therapeutic benefits of cognitive stimulation may be in part related to inhibition of expression of inflammatory genes. Together, the above evidence points to a role of PS on regulating directly or indirectly the expression of proinflammatory genes. Although the specific mechanisms by which PS repress expression of inflammatory genes are still unknown, it is tempting to speculate that PS $/ \gamma$-secretase-dependent mechanisms, such as that involving repression of astrocytic genes by the ErbB4 intracellular domain (Sardi et al., 2006), might be involved on transcriptional regulation of inflammatory genes during neurodegeneration (Figure 1).

\section{PS $/ \gamma$-SECRETASE AS PHARMACOLOGICAL TARGET OF NSAIDs}

Epidemiological studies indicate that chronic treatment with NSAIDs delays the onset and reduces the risk of AD (Stewart et al., 1997; McGeer and McGeer, 2007). Prospective population-based cohort studies revealed that NSAID use for more than 2 years decreases by $60-80 \%$ the risk of developing $\mathrm{AD}$ but not vascular dementia (Stewart et al., 1997; in t' Veld et al., 2001). Regular use of specific NSAIDs for 1 year or more than 5 years decreases the risk of AD significantly from $2 \%$ to $34 \%$, respectively (Vlad et al., 2008). For instance, ibuprofen and indomethacin, two NSAIDs that decrease $\mathrm{A} \beta 42$, showed a strong protective effect that increased with duration of use. By contrast, celecoxib and salicylates, two NSAIDs that do not affect $\mathrm{A} \beta 42$, did not show any protective effects (Vlad et al., 2008). Randomized clinical studies with indomethacin for 6 months improved cognitive function in mild/moderate $\mathrm{AD}$ patients, whereas naproxen, rofecoxib, diclofenac or nimesulide revealed no cognitive benefits (McGeer and McGeer, 2007). R-flurbiprofen, an enantiomer of flurbiprofen that selectively lower A $\beta 42$ and lacks COX inhibitory activity, did not slow cognitive decline or improved activities of daily living in phase III trials (Green et al., 2009). These differential effects of NSAIDs on AD may be caused by distinct activity of NSAIDs on COX-dependent or -independent mechanisms.

The molecular mechanisms by which NSAIDs reduce inflammation and ameliorate clinical symptoms in AD are largely unclear. The classical mechanism of anti-inflammatory action of NSAIDs involves reduction of prostaglandin synthesis through inhibition of COX enzymes (COX-1 and COX-2). NSAIDs have been also shown to activate the nuclear receptor peroxisome proliferator-activated receptor- $\gamma(\operatorname{PPAR} \gamma)$ and inhibit expression of proinflammatory genes. Alternatively, NSAIDs inhibit A $\beta 42$ generation by repressing BACE1 expression through PPAR $\gamma$ and by regulating the presenilin $/ \gamma$-secretase-dependent cleavage of APP (Weggen et al., 2007). In support of a role of some NSAIDs on protecting from $A \beta$ pathology through PPAR $\gamma$, it has been shown that NSAIDs repress BACE expression and negatively modulate $A \beta$ generation (Sastre et al., 2006), whereas acute treatments with ibuprofen or the PPAR $\gamma$ agonist pioglitazone reduce BACE1 expression and glial inflammation in APP transgenic mice (Heneka et al., 2005). On the other hand, some NSAIDs affect $\mathrm{A} \beta$ levels by modulating $\gamma$-secretase activity, the non amyloidogenic $\alpha$-secretase pathway and/or A $\beta$ aggregation (Weggen et al., 2007). For instance, NSAIDs bind to and inhibit formation of $A \beta$ fibrils in vitro (Agdeppa et al., 2003; Hirohata et al., 2005), a mechanism that may explain the beneficial effects of chronic treatment of ibu- profen or R-flurbiprofen on reducing amyloid deposits in very old APP transgenic mice (Lim et al., 2000; Kukar et al., 2007). A subset of NSAIDs induce a shift on the $\gamma$-secretase proteolytic cleavage of APP causing a specific decrease on the production of $A \beta 42$ while increasing shorter $A \beta$ species (i.e. $A \beta 38$ ) and without affecting $A \beta 40$ (Weggen et al., 2001). Indeed, the generation of $A \beta 42$ and $A \beta 38$ by $\gamma$-secretase is independent from each other and NSAID differentially affect the levels of these peptides. Thus, PS mutants that are insensitive to sulindac sulfide show a robust increase of A 338 (Page et al., 2008). Ibuprofen, sulindac sulfide and indomethacin, selectively decrease $A \beta 42$ peptides independently of COX inhibition, whereas R-flurbiprofen, which lacks COX inhibitory activity, decreases A $\beta 42$ levels in cell culture and APP transgenic models (Weggen et al., 2001). In addition, cell-based screenings identified a number of COX-2 selective NSAIDs that selectively raised A $\beta 42$, and some of these also decreased $A \beta 38$ (Kukar et al., 2005). These A $\beta 42$-raising NSAIDs seem to act independently of RhoA activity by modulating directly $\gamma$-secretase activity.

The mechanism of action of this subgroup of NSAIDs on $\gamma$-secretase activity is independent of COX inhibition and most likely involves allosteric modulation of the $\gamma$-secretase complex and/or binding to APP. The fact that these compounds are effective in lowering or raising $\mathrm{A} \beta 42$ in vitro in cell-free assays supports the notion that they act directly on $\gamma$-secretase (Eriksen et al., 2003; Kukar et al., 2005). In support of this view, A $\beta 42$-lowering NSAIDs change the conformation of presenilin-1 and alter the interaction of APP and presenilin $/ \gamma$-secretase (Lleo et al., 2004). This may explain why some $A \beta 42$-lowering NSAIDs reduce $A \beta 42$ generation without affecting the $\varepsilon$-cleavage of APP, Notch and ErbB4. Indeed, the selectivity of NSAID for targeting the $\gamma$-secretase cleavage of APP instead of other substrates may be explained by the specific binding of these compounds to APP (Kukar et al., 2008). Several familial AD-linked PS mutations attenuate the inhibitory effect of NSAIDs on $\mathrm{A} \beta 42$ production. The insensitivity of PS mutants to $A \beta 42$ lowering NSAIDs is mimicked by non-related structural $\gamma$-secretase inhibitors suggesting that the binding site of these compounds are located in close proximity within the $\gamma$-secretase complex (Czirr et al., 2007).

Several studies have shown that long-term treatment with specific NSAIDs reduces $A \beta$ pathology and inflammatory responses in APP transgenic mice. Ibuprofen markedly reduced soluble $A \beta 42$, amyloid plaques and microglia activation in APP Tg2576 mice by a mechanism independent of PPAR $\gamma$ (Yan et al., 2003). By contrast, acute treatment of old APPV717I transgenic mice with ibuprofen or the PPAR $\gamma$ agonist pioglitazone reduced glial inflammation and amyloid plaques by decreasing BACE1 expression (Heneka et al., 2005). Other studies using NSAIDs revealed similar reductions in insoluble $A \beta$ and inflammation, or unchanged $A \beta 40 / 42$ ratio but decreased A $\beta$ plaques in APP transgenic mice (Lim et al., 2000; Kukar et al., 2007; McGeer and McGeer, 2007). A recent study, however, revealed no advantage of A $\beta 42$-lowering NSAIDS for preventing from AD compared to classical NSAIDs (Szekely et al., 2008). Interestingly, therapeutic benefits have been reported with triflusal, an anti-inflammatory drug that inhibits COX-1 and delays the conversion of amnestic mild cognitive impairment to $\mathrm{AD}$ dementia. Triflusal reduced proinflammatory cytokine levels (IL$1 \beta$ and $\mathrm{TNF} \alpha$ ), dense-core plaques and neuritic dystrophy in APP 
Tg2576 transgenic mice (Coma et al., 2010). In old APP Tg2576 mice, triflusal efficiently rescued spatial and associative memory deficits and expression of genes activated by CREB, a signaling pathway underlying the molecular basis of synaptic plasticity (Coma et al., 2010). Despite the mechanism of action and the controversy in human trials, NSAIDs effectively reduces amyloid pathology and inflammation in AD transgenic mice. It is conceivable that the protective effect of NSAIDs on AD pathology may be mediated by multiple mechanisms including among others COX, PPAR $\gamma$, $\gamma$-secretase or a combination of these pathways.

\section{CONCLUDING REMARKS}

A large number of studies over the past years have revealed that PS regulate multiple signaling pathways in neurons and glia. For instance, the $\gamma$-secretase-dependent cleavage of APP generates the $\mathrm{A} \beta$ peptide, which plays a central role on $\mathrm{AD}$ pathogenesis by disrupting synaptic and metabolic processes essential for neuron survival. Several pathological hallmarks, including inflammation, are exacerbated by presenilin mutations that cause early-onset familial AD or FTD. These studies strongly suggest $\gamma$-secretase as potential therapeutic target to reduce $A \beta$-induced pathology and clinical symptoms in AD. This therapeutic approach was successful in mice, in which partial inactivation of PS efficiently reduced age-dependent $A \beta$ accumulation and temporally rescued memory deficits in an AD mouse model (Dewachter et al., 2002; Saura et al., 2005). However, clinical treatment with the $\gamma$-secretase inhibitor LY450139 in AD patients, although was well tolerated and reduced plasma $A \beta 40$ levels, did not result in significant differences in cognitive or functional measures. Similarly, NSAIDs that reduce $A \beta$-associated pathology and inflammation in $A D$ transgenic mice revealed no advantage for preventing from $\mathrm{AD}$ compared to classical NSAIDs (Szekely et al., 2008). Notably, targeting the Notch pathway by using $\gamma$-secretase inhibitors has been

\section{REFERENCES}

Agdeppa, E. D., Kepe, V., Petri, A., Satyamurthy, N., Liu, J., Huang, S. C., Small, G. W., Cole, G. M., and Barrio, J. R. (2003). In vitro detection of (S)naproxen and ibuprofen binding to plaques in the Alzheimer's brain using the positron emission tomography molecular imaging probe 2-(1-[6-[(2-[(18)F]fluoroethyl) (me thyl)amino]-2-naphthyl] ethylidene) malono nitrile. Neuroscience 117, 723-730.

Allan, S. M., and Rothwell, N. J. (2003). Inflammation in central nervous system injury. Philos. Trans. R. Soc. Lond., B, Biol. Sci. 358, 1669-1677.

Arumugam, T. V., Chan, S. L., Jo, D. G., Yilmaz, G., Tang, S. C., Cheng, A., Gleichmann, M., Okun, E., Dixit, V.D., Chigurupati,S.,Mughal,M.R.,Ouyang, X., Miele, L., Magnus, T., Poosala, S., Granger, D. N., and Mattson, M. P. (2006). Gamma secretase-mediated Notch signaling worsens brain damage and functional outcome in ischemic stroke. Nat. Med. 12, 621-623.
Bamberger, M. E., Harris, M. E., McDonald, D. R., Husemann, J., and Landreth, G. E. (2003). A cell surface receptor complex for fibrillar $\beta$-amyloid mediates microglial activation. $J$. Neurosci. 23, 2665-2674.

Bates, K. A., Fonte, J., Robertson, T. A., Martins, R. N., and Harvey, A. R. (2002). Chronic gliosis triggers Alzheimer's disease-like processing of amyloid precursor protein. Neuroscience 113, 785-796.

Beglopoulos, V., Sun, X., Saura, C. A., Lemere, C. A., Kim, R. D., and Shen, J. (2004). Reduced $\beta$-amyloid production and increased inflammatory responses in presenilin conditional knock-out mice. J. Biol. Chem. 279, 46907-46914.

Bernardi, L., Tomaino, C., Anfossi, M., Gallo, M., Geracitano, S., Costanzo, A., Colao, R., Puccio, G., Frangipane, F., Curcio, S.A., Mirabelli, M., Smirne, N., Iapaolo, D., Maletta, R. G., and Bruni, A.C. (2009). Novel PSEN1 and PGRN mutations in early-onset familial frontotemporal dementia.Neurobiol. Aging $30,1825-1833$

suggested as therapeutic approach in cancer disorders caused by aberrant Notch signaling such as T-cell acute lymphoblastic leukemia, breast cancer and ovarian carcinomas (Shih and Wang, 2007). However, pharmacological inhibition of PS/ $\gamma$-secretase during AD therapeutics may have detrimental effects not only for systemic immune function but also for epidermal and skin barrier homeostasis (Rocher-Ros et al., 2010). Before clinical treatments, future studies should focus primarily on dissecting target specificity of $\gamma$-secretase modulators. Nonetheless, inactivation of PS function in the forebrain results in synaptic and cognitive dysfunction followed by neurodegeneration (Saura et al., 2004). PS inactivation in brain also causes inflammatory responses in brain and periphery organs. In addition, compelling evidence indicate that PS/ $\gamma$-secretase regulates maturation of T cells by regulating the Notch signaling pathway, whereas its inactivation causes side effects on immune function. Taking into consideration that $\mathrm{PS} / \gamma$-secretase plays an essential function on multiple signaling pathways, a better understanding of the molecular mechanisms regulated by PS in inflammation may lead to the development of novel therapeutic strategies for disorders of the nervous and immune systems.

\section{USE OF EXPERIMENTAL ANIMALS}

All experiments shown in this study were performed in accordance with institutional and national guidelines following approval by the Animal Care and Ethical Committee of the Universitat Autònoma de Barcelona.

\section{ACKNOWLEDGMENTS}

This work was supported by grants from Ministerio de Ciencia e Innovación of Spain (SAF2007-64115 and CIBERNED CB06/05/0042), Fundació Marató-TV3 (050710) and 7th Framework Programme of the European Union (MEMOSAD project, grant 200611).

Cervantes, S., Saura, C. A., Pomares, E. Gonzalez-Duarte, R., and Marfany, G. (2004). Functional implications of the presenilin dimerization: reconstitution of $\gamma$-secretase activity by assembly of a catalytic site at the dimer interface of two catalytically inactive presenilins. $J$. Biol. Chem. 279, 36519-36529.

Choi,S.H., Veeraraghavalu, K., Lazarov, O. Marler, S., Ransohoff, R. M., Ramirez, J. M., and Sisodia, S. S. (2008). Noncell-autonomous effects of presenilin 1 variants on enrichment-mediated hippocampal progenitor cell proliferation and differentiation. Neuron 59, 568-580.

Coma, M., Sereno, L., Da Rocha-Souto, B., Scotton, T. C., España, J., Sánchez, M. B., Rodríguez, M., Agulló, J. Guardia-Laguarta, C., Garcia-Alloza, M., Borreli, L. A., Clarimón, J., Lleó, A, Bacskai, B. J., Saura, C. A., Hyman, B., and Gómez-Isla, T. (2010). Triflusal reduces dense-core plaque load, associated axonal alterations and inflammatory changes, and rescues cognition in a transgenic mouse model of
Alzheimer's disease. Neurobiol. Dis. (in press). [Epub ahead of print].

Czirr, E., Leuchtenberger, S., DornerCiossek, C., Schneider, A., Jucker, M., Koo, E. H., Pietrzik, C. U., Baumann, K., and Weggen, S. (2007). Insensitivity to A $\beta 42$-lowering nonsteroidal antiinflammatory drugs and $\gamma$-secretase inhibitors is common among aggressive presenilin-1 mutations. J. Biol. Chem. 282, 24504-24513.

Dermaut,B.,Kumar-Singh,S.,Engelborghs, S., Theuns, J., Rademakers, R., Saerens, J., Pickut, B. A., Peeters, K., Van Den Broeck, M., Vennekens, K., Claes, S. Cruts, M., Cras, P., Martin, J. J., Van Broeckhoven, C., and De Deyn, P. P. (2004). A novel presenilin 1 mutation associated with Pick's disease but not $\beta$-amyloid plaques. Ann. Neurol. 55, 617-626.

De Strooper, B. (2003). Aph-1, pen-2, and nicastrin with presenilin generate an active $\gamma$-secretase complex. Neuron 38, 9-12.

De Strooper, B. (2007). Loss-of-function presenilin mutations in Alzheimer 
disease. Talking Point on the role of presenilin mutations in Alzheimer disease. EMBO Rep. 8, 141-146.

De Strooper, B., Annaert, W., Cupers, P., Saftig, P., Craessaerts, K., Mumm, J. S., Schroeter, E. H., Schrijvers, V., Wolfe, M.S., Ray, W. J., Goate, A., and Kopan, R. (1999). A presenilin-1-dependent $\gamma$-secretase-like protease mediates release of Notch intracellular domain. Nature 398, 518-522.

De Strooper, B., Saftig, P., Craessaerts, K., Vanderstichele, H., Guhde, G., Annaert, W., Figura, K., and Leuven, F. (1998). Deficiency of presenilin-1 inhibits the normal cleavage of amyloid precursor protein. Nature 391, 387-390.

Dewachter, I., Reverse, D., Caluwaerts, N., Ris, L., Kuiperi, C., Van den Haute, C., Spittaels, K., Umans, L., Serneels, L., Thiry, E., Moechars, D., Mercken, M., Godaux, E., and Van Leuven, F. (2002). Neuronal deficiency of presenilin 1 inhibits amyloid plaque formation and corrects hippocampal long-term potentiation but not a cognitive defect of amyloid precursor protein [V717I] transgenic mice. J. Neurosci. 22, 3445-3453.

Dewachter, I., Ris, L., Croes, S., Borghgraef, P., Devijver, H., Voets, T., Nilius, B., Godaux, E., and Van Leuven, F. (2008). Modulation of synaptic plasticity and Tau phosphorylation by wild-type and mutant presenilin1. Neurobiol. Aging 29, 639-652.

Dong, S., Li, C., Wu, P., Tsien, J. Z., and $\mathrm{Hu}$, Y. (2007). Environment enrichment rescues the neurodegenerative phenotypes in presenilins-deficient mice. Eur. J. Neurosci. 26, 101-112.

Dumanchin, C., Tournier, I., Martin, C., Didic, M., Belliard, S., Carlander, B., Rouhart, F., Duyckaerts, C., Pellissier, J. F., Latouche, J. B., Hannequin, D., Frebourg, T., Tosi, M., and Campion, D. (2006). Biological effects of four PSEN1 gene mutations causing Alzheimer disease with spastic paraparesis and cotton wool plaques. Hum. Mutat. 27, 1063.

Eckert, A., Schindowski, K., Leutner, S., Luckhaus, C., Touchet, N., Czech, C., and Muller, W. E. (2001). Alzheimer's disease-like alterations in peripheral cells from presenilin-1 transgenic mice. Neurobiol. Dis. 8, 331-342.

Eikelenboom, P., and Veerhuis, R. (1996). The role of complement and activated microglia in the pathogenesis of Alzheimer's disease. Neurobiol. Aging 17, 673-680.

Eriksen, J. L., Sagi, S. A., Smith, T. E., Weggen, S., Das, P., McLendon, D. C., Ozols, V. V., Jessing, K. W., Zavitz, K. H., Koo, E. H., and Golde, T. E. (2003). NSAIDs and enantiomers of flurbiprofen target $\gamma$-secretase and lower A 342 in vivo. J. Clin. Invest. 112, 440-449.

Gaiano, N., and Fishell, G. (2002). The role of notch in promoting glial and neural stem cell fates. Annu. Rev. Neurosci. 25, 471-490.

Gaiano, N., Nye, J., and Fishell, G. (2000). Radial glial identity is promoted by Notch 1 signaling in the murine forebrain. Neuron 26, 395-404.

Gomez-Isla, T., Growdon, W. B., McNamara, M. J., Nochlin, D., Bird, T. D., Arango, J. C., Lopera, F., Kosik, K. S., Lantos, P. L., Cairns, N. J., and Hyman, B. T. (1999). The impact of different presenilin 1 and presenilin 2 mutations on amyloid deposition, neurofibrillary changes and neuronal loss in the familial Alzheimer's disease brain: evidence for other phenotypemodifying factors. Brain 122(Pt 9), 1709-1719.

Gomez-Tortosa, E., Barquero, S., Baron, M., Gil-Neciga, E., Castellanos, F. Zurdo, M., Manzano, S., Munoz, D. G., Jimenez-Huete, A., Rabano, A., Sainz, M. J., Guerrero, R., Gobernado, I., Perez-Perez, J., and Jimenez-Escrig, A. (2010). Clinical-genetic correlations in familial Alzheimer's disease caused by presenilin 1 mutations. J. Alzheimers Dis. 19, 873-884.

Green, R. C., Schneider, L. S., Amato, D. A., Beelen, A. P., Wilcock, G., Swabb, E. A., and Zavitz, K. H. (2009). Effect of tarenflurbil on cognitive decline and activities of daily living in patients with mild Alzheimer disease: a randomized controlled trial. JAMA 302, 2557-2564.

Gregory, G. C., Macdonald,V., Schofield,P. R., Kril, J. J., and Halliday, G. M. (2006). Differences in regional brain atrophy in genetic forms of Alzheimer's disease. Neurobiol. Aging 27, 387-393.

Handler, M., Yang, X., and Shen, J. (2000). Presenilin-1 regulates neuronal differentiation during neurogenesis. Development 127, 2593-2606.

Hardy, J., and Selkoe, D. (2002). The amyloid hypothesis of Alzheimer's disease: progress and problems on the road to therapeutics. Science 297, 353-356.

Heneka, M. T., Sastre, M., DumitrescuOzimek, L., Hanke, A., Dewachter, I., Kuiperi, C., O'Banion, K., Klockgether, T., Van Leuven, F., and Landreth, G. E. (2005). Acute treatment with the PPAR $\gamma$ agonist pioglitazone and ibuprofen reduces glial inflammation and A $\beta 1-42$ levels in APPV717I transgenic mice. Brain 128, 1442-1453.

Hirohata, M., Ono, K., Naiki, H., and Yamada, M. (2005). Non-steroidal anti-inflammatory drugs have anti-amyloidogenic effects for Alzheimer's $\beta$-amyloid fibrils in vitro. Neuropharmacology 49, 1088-1099.
Holmes, C., Cunningham, C., Zotova, E., Woolford, J., Dean, C., Kerr, S. Culliford, D., and Perry, V. H. (2009). Systemic inflammation and disease progression in Alzheimer disease. Neurology 73, 768-774.

Hutton, M. (2004). Presenilin mutations associated with fronto-temporal dementia. Ann. Neurol. 55, 604-606.

Ingelsson, M., Fukumoto, H., Newell, K. L., Growdon, J. H., Hedley-Whyte, E. T., Frosch, M. P., Albert, M. S., Hyman, B. T., and Irizarry, M. C. (2004). Early $\mathrm{A} \beta$ accumulation and progressive synaptic loss, gliosis, and tangle formation in AD brain. Neurology 62, 925-931.

in t' Veld, B. A., Ruitenberg, A., Hofman, A., Launer, L. J., van Duijn, C. M., Stijnen, T., Breteler, M. M., and Stricker, B. H. (2001). Nonsteroidal antiinflammatory drugs and the risk of Alzheimer's disease. N. Engl. J. Med. 345, 1515-1521.

Jack, C., Knopman, D., Jagust, W., Shaw, L. Aisen, P., Weiner, M., Petersen, R., and Tojanowski, J. (2010). Hypothetical model of dynamic biomarkers of the Alzheimer's pathological cascade. Lancet Neurol. 9, 119-128.

Jiang, X., Zhang, D., Shi, J., Chen, Y., Zhang, P., and Mei, B. (2009). Increased inflammatory response both in brain and in periphery in presenilins conditional double knock-out mice. $J$. Alzheimers Dis. 18, 515-523.

Johnston, J. M., Burnett, P., Thomas, A P., and Tezapsidis, N. (2006). Calcium oscillations in type- 1 astrocytes, the effect of a presenilin 1 (PS1) mutation. Neurosci. Lett. 395, 159-164.

Kim, K. S., Wegiel, J., Sapienza, V., Chen, J., Hong, H., and, Wisniewski, H. M. (1997). Immunoreactivity of presenilin-1 in human, rat and mouse brain. Brain Res. 757, 159-163.

Koo, E. H., and Kopan, R. (2004). Potential role of presenilin-regulated signaling pathways in sporadic neurodegeneration. Nat. Med. 10(Suppl.), S26-S33.

Kukar, T., Murphy, M. P., Eriksen, J. L. Sagi, S. A., Weggen, S., Smith, T. E., Ladd, T., Khan, M.A., Kache, R., Beard, J., Dodson, M., Merit, S., Ozols, V. V., Anastasiadis, P. Z., Das, P., Fauq, A., Koo, E. H., and Golde, T. E. (2005) Diverse compounds mimic Alzheimer disease-causing mutations by augmenting A $\beta 42$ production. Nat. Med. 11, 545-550.

Kukar, T., Prescott, S., Eriksen, J. L. Holloway, V., Murphy, M. P., Koo, E H., Golde, T. E., and Nicolle, M. M. (2007). Chronic administration of R-flurbiprofen attenuates learning impairments in transgenic amyloid precursor protein mice. $B M C$ Neurosci. 8, 54.

Kukar, T. L., Ladd, T. B., Bann, M. A., Fraering, P. C., Narlawar, R., Maharvi,
G. M., Healy, B., Chapman, R., Welzel, A. T., Price, R. W., Moore, B., Rangachari, V., Cusack, B., Eriksen, J., Jansen-West, K., Verbeeck, C., Yager, D., Eckman, C., Ye, W., Sagi, S., Cottrell, B. A., Torpey, J., Rosenberry, T. L., Fauq, A., Wolfe, M.S., Schmidt, B., Walsh, D. M., Koo, E.H., and Golde, T.E. (2008). Substrate-targeting $\gamma$-secretase modulators. Nature 453, 925-929.

Kumar-Singh, S., Theuns, J., Van Broeck, B., Pirici, D., Vennekens, K., Corsmit, E., Cruts, M., Dermaut, B., Wang, R., and Van Broeckhoven, C. (2006). Mean age-of-onset of familial Alzheimer disease caused by presenilin mutations correlates with both increased $\mathrm{A} \beta 42$ and decreased A $\beta 40$. Hum. Mutat. 27, 686-695.

Lah, J. J., Heilman, C. J., Nash, N. R., Rees, H. D., Yi, H., Counts, S. E., and Levey, A. I. (1997). Light and electron microscopic localization of presenilin 1 in primate brain. J. Neurosci. 17, 1971.

Laky, K., and Fowlkes, B. J. (2007). Presenilins regulate alphabeta $\mathrm{T}$ cell development by modulating TCR signaling. J. Exp. Med. 204, 2115-2129.

Laky, K., and Fowlkes, B. J. (2008). Notch signaling in CD4 and CD8 T cell development. Curr. Opin. Immunol. 20, 197-202.

Lathia, J. D., Mattson, M. P., and Cheng, A. (2008). Notch: from neural development to neurological disorders. J. Neurochem. 107, 1471-1481.

Le, T.V., Crook, R., Hardy, J., and Dickson, D. W. (2001). Cotton wool plaques in non-familial late-onset Alzheimer disease. J. Neuropathol. Exp. Neurol. 60, 1051-1061.

Lee, M. K., Slunt, H. H., Martin, L. J. Thinakaran, G., Kim, G., Gandy, S. E., Seeger, M., Koo, E., Price, D. L., and Sisodia, S. S. (1996). Expression of presenilin 1 and 2 (PS1 and PS2) in human and murine tissues. J. Neurosci. 16, 7513-7525.

Lemere, C. A., Munger, J. S., Shi, G.-P., Natkin, L., Haass, C., Chapman, H. A., and Selkoe, D. J. (1995). The lysosomal cystein protease, cathepsin S, is increased in Alzheimer's disease and Down syndrome brain: an immunocytochemical study. Am. J. Pathol. 146, 848-860.

Levy-Lahad, E., Wasco, W., Poorkaj, P., Romano, D. M., Oshima, J., Pettingell, H., Yu, C., Jondro, P. D., Schmidt, S. D., Wang, K., Crowley, A. C., Fu, Y-H, Guenette, S. Y., Galas, D., Nemens, E., Wijsman, E. M., Bird, T. D., Schellenberg, G. D., and Tanzi, R. E. (1995). Candidate gene for the chromosome 1 familial Alzheimer's disease locus. Science 269, 973-977.

Lim, G. P., Yang, F., Chu, T., Chen, P., Beech, W., Teter, B., Tran, T., Ubeda, O., Ashe, K. H., Frautschy, S. A., and Cole, 
G. M. (2000). Ibuprofen suppresses plaque pathology and inflammation in a mouse model for Alzheimer's disease. J. Neurosci. 20, 5709-5714.

Lippa, C. F., Saunders, A. M., Smith, T. W., Swearer, J. M., Drachman, D. A., Ghetti, B., Nee, L., Pulaski-Salo, D., Dickson, D., Robitaille, Y., Bergeron, C., Crain, B., Benson, M. D., Farlow, M., Hyman, B. T., George-Hyslop, S. P., Roses, A. D., and Pollen, D. A. (1996). Familial and sporadic Alzheimer's disease: neuropathology cannot exclude a final common pathway. Neurology 46, 406-412.

Lleo, A., Berezovska, O., Herl, L., Raju, S., Deng, A., Bacskai, B. J., Frosch, M. P., Irizarry, M., and Hyman, B. T. (2004). Nonsteroidal anti-inflammatory drugs lower $A \beta 42$ and change presenilin 1 conformation. Nat. Med. 10, 1065-1066.

Lynch, M.A. (2010). Age-related neuroinflammatory changes negatively impact on neuronalfunction.Front. Neurosci. 1, 1-8. doi: 10.3389/neuro.24.006.2009.

Mann, D. M., Takeuchi, A., Sato, S., Cairns, N. J., Lantos, P. L., Rossor, M. N., Haltia, M., Kalimo, H., and Iwatsubo, T. (2001). Cases of Alzheimer's disease due to deletion of exon 9 of the presenilin-1 gene show an unusual but characteristic $\beta$-amyloid pathology known as 'cotton wool' plaques. Neuropathol. Appl. Neurobiol. 27, 189-196.

Maraver, A., Tadokoro, C. E., Badura, M. L., Shen, J., Serrano, M., and Lafaille, J. J. (2007). Effect of presenilins in the apoptosis of thymocytes and homeostasis of CD8+ T cells. Blood 110, 3218-3225.

Martikainen, P., Pikkarainen, M., Pontynen, K., Hiltunen, M., Lehtovirta, M., Tuisku, S., Soininen, H., and Alafuzoff, I. (2009). Brain pathology in three subjects from the same pedigree with PSEN1 P264L mutation. Neuropathol. Appl. Neurobiol. 36, 41-54.

McGeer, P. L., and McGeer, E. G. (2007). NSAIDs and Alzheimer disease: epidemiological, animal model and clinical studies. Neurobiol. Aging 28, 639-647.

Moore, A. H., Wu, M., Shaftel, S. S., Graham, K. A., and O'Banion, M. K. (2009). Sustained expression of interleukin-1beta in mouse hippocampus impairs spatial memory. Neuroscience 164, 1484-1495.

Morgan, G. A., Guo, Q., Chan, S. L., Gary, D. S., Osborne, B. A., and Mattson, M. P. (2007). Defects of immune regulation in the presenilin-1 mutant knockin mouse. Neuromol. Med. 9, 35-45.

Mrak, R. E., and Griffin, W. S. (2005). Glia and their cytokines in progression of neurodegeneration. Neurobiol. Aging 26, 349-354.

Muller, T., Meyer, H. E., Egensperger, R., and Marcus, K. (2008). The amyloid precursor protein intracellular domain (AICD) as modulator of gene expression, apoptosis, and cytoskeletal dynamics-relevance for Alzheimer's disease. Prog. Neurobiol. 85, 393-406.

Munch, G., Gasic-Milenkovic, J., DukicStefanovic, S., Kuhla, B., Heinrich, K. Riederer, P., Huttunen, H. J., Founds, H., and Sajithlal, G. (2003). Microglial activation induces cell death, inhibits neurite outgrowth and causes neurite retraction of differentiated neuroblastoma cells. Exp. Brain. Res. 150, 1-8.

Nadler, Y., Alexandrovich, A., Grigoriadis, N., Hartmann, T., Rao, K. S., Shohami, E., and Stein, R. (2008). Increased expression of the $\gamma$-secretase components presenilin-1 and nicastrin in activated astrocytes and microglia following traumatic brain injury. Glia 56, 552-567.

Nagele, R. G., D’Andrea, M. R., Lee, H., Venkataraman, V., and Wang, H. Y. (2003). Astrocytes accumulate $A \beta 42$ and give rise to astrocytic amyloid plaques in Alzheimer disease brains. Brain Res. 971, 197-209.

Ni, C., Murphy, M., Golde, T., and Carpenter, G. (2001). $\gamma$-Secretase cleavage and nuclear localization of ErbB-4 receptor tyrosine kinase. Science 294, 2179-2181.

Nochlin, D., van Belle, G., Bird, T. D., and Sumi, S.M. (1993). Comparison of the severity of neuropathologic changes in familial and sporadic Alzheimer's disease. Alzheimer Dis. Assoc. Disord. 7, 212-222.

Ong, C. T., Sedy, J. R., Murphy, K. M., and Kopan, R. (2008). Notch and presenilin regulate cellular expansion and cytokine secretion but cannot instruct Th1/Th2 fate acquisition. PLoS ONE 3, e2823. doi:10.1371/journal. pone. 0002823

Page, R. M., Baumann, K., Tomioka, M., Perez-Revuelta, B. I, Fukumori, A., Jacobsen, H., Flohr, A., Luebbers, T., Ozmen, L., Steiner, H., and Haass, C. (2008). Generation of $A \beta 38$ and $A \beta 42$ is independently and differentially affected by familial Alzheimer diseaseassociated presenilin mutations and $\gamma$-secretase modulation. J. Biol. Chem. 283, 677-683.

Parachikova, A., Agadjanyan, M. G., Cribbs, D. H., Blurton-Jones, M., Perreau, V., Rogers, J., Beach, T. G., and Cotman, C. W. (2007). Inflammatory changes parallel the early stages of Alzheimer disease. Neurobiol. Aging 28, 1821-1833.

Peers, C., Dallas, M. L., Boycott, H. E., Scragg, J. L., Pearson, H. A., and
Boyle, J. P. (2009). Hypoxia and neurodegeneration. Ann. N. Y. Acad. Sci. 1177, 169-177.

Peers, C., Smith, I. F., Boyle, J. P., and Pearson, H. A. (2004). Remodelling of $\mathrm{Ca}^{2+}$ homeostasis in type I cortical astrocytes by hypoxia: evidence for association with Alzheimer's disease. Biol. Chem. 385, 285-289.

Raux, G., Gantier, R., Thomas-Anterion, C., Boulliat, J., Verpillat, P., Hannequin, D., Brice, A., Frebourg, T., and Campion, D. (2000). Dementia with prominent frontotemporal features associated with L113P presenilin 1 mutation. Neurology 55, 1577-1578.

Rocher-Ros, V., Marco, S., Mao, J. H. Gines, S., Metzger, D., Chambon, P. Balmain, A., and Saura, C. A. (2010). Presenilin modulates EGFR signaling and cell transformation by regulating the ubiquitin ligase Fbw7. Oncogene (in press). [Epub ahead of print]

Rogaev, E. I., Sherrington, R., Rogaeva, E. A., Levesque, G., Ikeda, M., Liang, Y., Chi, H., Lin, C., Holamn, K., Tsuda, T., Mar, L., Sorbi, S., Nacmias, B., Piacentini, S., Amaducci, L., Chumakov, I., Cohen, D., Lannfelt, L., Fraser, P. E., Rommens, J. M., and St. George-Hyslop, P. H. (1995). Familial Alzheimer's disease in kindreds with missense mutations in a gene on chromosome 1 related to the Alzheimer's disease type 3 gene. Nature 376, 775-778.

Sardi, S. P., Murtie, J., Koirala, S., Patten, B. A., and Corfas, G. (2006). Presenilindependent ErbB4 nuclear signaling regulates the timing of astrogenesis in the developing brain. Cell 127, 185-197.

Sastre, M., Dewachter, I., Rossner, S., Bogdanovic, N., Rosen, E., Borghgraef, P., Evert, B. O., Dumitrescu-Ozimek, L., Thal, D. R., Landreth, G., Walter J., Klockgether, T., van Leuven, F., and Heneka, M. T. (2006). Nonsteroidal anti-inflammatory drugs repress $\beta$ secretase gene promoter activity by the activation of PPARgamma. Proc. Natl. Acad. Sci. U.S.A. 103, 443-448.

Saura, C.A., Chen, G., Malkani, S., Choi, S. Y., Takahashi, R.H., Zhang, D., Gouras, G. K., Kirkwood, A., Morris, R. G., and Shen, J. (2005). Conditional inactivation of presenilin-1 prevents amyloid accumulation and temporarily rescues contextual and spatial working memory impairments in amyloid precursor protein transgenic mice. J. Neurosci. 25, 6755-6764.

Saura, C. A., Choi, S. Y., Beglopoulos, V., Malkani, S., Zhang, D., Shankaranarayana Rao, B. S., Chattarji, S., Kelleher, R. J. III, Kandel, E. R., Duff, K., Kirkwood, A., and Shen, J. (2004). Loss of presenilin function causes impairments of memory and synaptic plasticity followed by age-dependent neurodegeneration. Neuron 42 , 23-36.

Saura, C. A., Tomita, T., Davenport, F., Harris, C. L., Iwatsubo, T., and Thinakaran, G. (1999). Evidence that intramolecular associations between presenilin domains are obligatory for endoproteolytic processing. J. Biol. Chem. 274, 13818-13823.

Selkoe, D. J. (2002). Alzheimer's disease is a synaptic failure. Science 298 , 789-791.

Shen, J., and Kelleher R. J. III. (2007). The presenilin hypothesis of Alzheimer's disease: evidence for a loss-of-function pathogenic mechanism. Proc. Natl. Acad. Sci. U.S.A. 104, 403-409.

Shepherd, C., McCann, H., and Halliday, G. M. (2009). Variations in the neuropathology of familial Alzheimer's disease. Acta Neuropathol. 118, 37-52.

Shepherd, C. E., Grace, E. M., Mann, D. M., and Halliday, G. M. (2007). Relationship between neuronal loss and 'inflammatory plaques' in early onset Alzheimer's disease. Neuropathol. Appl. Neurobiol. 33, 328-333.

Shepherd, C. E., Gregory, G. C., Vickers, J. C., and Halliday, G. M. (2005). Novel 'inflammatory plaque' pathology in presenilin-1 Alzheimer's disease. Neuropathol. Appl. Neurobiol. 31, 503-511.

Sherrington, R., Rogaev, E. I., Liang, Y., Rogaeva, E. A., Levesque, G., Ikeda, M., Chi, H., Lin, C., Li, G., Holman, K., Tsuda, T., Mar, L., Foncin, J-F, Bruni, A. C., Montesi, M. P., Sorbi, S., Rainero, I., Pinessi, L., Nee, L., Chumakov, I., Pollen, D. A., Roses, A. D., Fraser, P. E., Rommens, J. M., and St. GeorgeHyslop, P. H. (1995). Cloning of a novel gene bearing missense mutations in early onset familial Alzheimer's disease. Nature 375, 754-760.

Shih, I. M., and Wang, T. L. (2007). Notch signaling, $\gamma$-secretase inhibitors, and cancer therapy. Cancer Res. 67, 1879-1882.

Sokolova, A., Hill, M. D., Rahimi, F., Warden, L. A., Halliday, G. M., and Shepherd, C.E. (2009). Monocyte chemoattractant protein-1 plays a dominant role in the chronic inflammation observed in Alzheimer's disease. Brain Pathol. 19, 392-398.

Stewart, W. F., Kawas, C., Corrada, M., and Metter,E. J. (1997). Risk of Alzheimer's disease and duration of NSAID use. Neurology 48, 626-632.

Sudo, S., Shiozawa, M., Cairns, N. J., and Wada, Y. (2005). Aberrant accentuation of neurofibrillary degeneration in the hippocampus of Alzheimer's disease with amyloid precursor protein 
717 and presenilin-1 gene mutations. J. Neurol. Sci. 234, 55-65.

Szekely, C. A., Green, R. C., Breitner, J. C. Ostbye, T., Beiser, A. S., Corrada, M. M., Dodge, H. H., Ganguli, M., Kawas, C. H., Kuller, L. H., Psaty, B. M., Resnick, S. M., Wolf, P. A., Zonderman, A. B., Welsh-Bohmer, K. A., and Zandi, P. P. (2008). No advantage of A 342 -lowering NSAIDs for prevention of Alzheimer dementia in six pooled cohort studies. Neurology 70, 2291-2298.

Takasugi, N., Tomita, T., Hayashi, I., Tsuruoka, M., Niimura, M., Takahashi, Y., Thinakaran, G., and Iwatsubo, T. (2003). The role of presenilin cofactors in the $\gamma$-secretase complex. Nature 422, 438-441.

Tenner, A. J. (2001). Complement in Alzheimer's disease: opportunities for modulating protective and pathogenic events. Neurobiol. Aging 22, 849-861.

Thinakaran, G., Borchelt, D. R., Lee, M. K., Slunt, H. H., Spitzer, L., Kim, G., Rotovitsky, T., Davenport, F., Nordstedt, C., Seeger, M., Hardy, J., Levey, A. I., Gandy, S. E., Jenkins, N. A., Copeland, N. G., Price, D. L., and Sisodia, S. S. (1996). Endoproteolysis of presenilin 1 and accumulation of processed derivatives in vivo. Neuron 17, 181-190.

Tournoy, J., Bossuyt, X., Snellinx, A., Regent, M., Garmyn, M., Serneels, L., Saftig, P., Craessaerts, K., De Strooper,
B., and Hartmann, D. (2004). Partial loss of presenilins causes seborrheic keratosis and autoimmune disease in mice. Hum. Mol. Genet. 13, 1321-1331.

Vlad, S. C., Miller, D. R., Kowall, N. W., and Felson, D. T. (2008). Protective effects of NSAIDs on the development of Alzheimer disease. Neurology 70, 1672-1677.

Weggen, S., Diehlmann, A., Buslei, R., Beyreuther, K., and Bayer, T.A. (1998). Prominent expression of presenilin-1 in senile plaques and reactive astrocytes in Alzheimer's disease brain. Neuroreport 9, 3279-3283.

Weggen, S., Eriksen, J. L., Das, P., Sagi, S. A., Wang, R., Pietrzik, C. U., Findlay, K. A., Smith, T. E., Murphy, M. P., Bulter, T., Kang, D. E., MarquezSterling, N., Golde, T. E., and Koo, E. H. (2001). A subset of NSAIDs lower amyloidogenic $A \beta 42$ independently of cyclooxygenase activity. Nature 414, 212-216.

Weggen, S., Rogers, M., and Eriksen, J. (2007). NSAIDs: small molecules for prevention of Alzheimer's disease or precursors for future drug development? Trends Pharmacol. Sci. 28, 536-543.

Weyand, N. J., Calton, C. M., Higashi, D. L., Kanack, K. J., and So, M. (2010). Presenilin $/ \gamma$-secretase cleaves CD46 in response to Neisseria infection. J. Immunol. 184, 694-701.
Woodhouse,A., Shepherd, C.E., Sokolova, A., Carroll, V. L., King, A. E., Halliday, G. M., Dickson, T. C., and Vickers J. C. (2009). Cytoskeletal alterations differentiate presenilin- 1 and sporadic Alzheimer's disease. Acta Neuropathol. 117, 19-29.

Wyss-Coray, T., Lin, C., Yan, F., Yu, G.-Q. Rohde, M., McConlogue, L., Masliah, E., and Mucke, L. (2001). TGF- $\beta 1$ promotes microglial amyloid- $\beta$ clearance and reduces plaque burden in transgenic mice. Nat. Med. 7, 612-618.

Wyss-Coray, T., Loike, J. D., Brionne, T. C. Lu, E., Anankov, R., Yan, F., Silverstein, S. C., and Husemann, J. (2003). Adult mouse astrocytes degrade amyloid$\beta$ in vitro and in situ. Nat. Med. 9 , 453-457.

Yagi, T., Giallourakis, C., Mohanty, S. Scheidig, C., Shen, J., Zheng, H., Xavier, R. J., and Shaw, A. C. (2008). Defective signal transduction in B lymphocytes lacking presenilin proteins. Proc. Natl. Acad. Sci. U.S.A. 105, 979-984.

Yan, Q., Zhang, J., Liu, H., Babu-Khan, S., Vassar, R., Biere, A. L., Citron, M. and Landreth, G. (2003). Anti-inflammatory drug therapy alters $\beta$-amyloid processing and deposition in an animal model of Alzheimer's disease. J. Neurosci. 23, 7504-7509.

Zekanowski, C., Golan, M. P., Krzysko, K. A., Lipczynska-Lojkowska, W. Filipek, S., Kowalska, A., Rossa, G., Peplonska, B., Styczynska, M.,
Maruszak, A., Religa, D., Wender, M., Kulczycki, J., Barcikowska, M. and Kuznicki, J. (2006). Two novel presenilin 1 gene mutations connected with frontotemporal dementia-like clinical phenotype: genetic and bioinformatic assessment. Exp. Neurol. 200, 82-88.

Zhang, Z., Nadeau, P., Song, W., Donoviel, D., Yuan, M., Bernstein, A., and Yankner, B. (2000). Presenilins are required for $\gamma$-secretase cleavage of $\beta$-APP and transmembrane cleavage of Notch-1. Nat. Cell Biol. 2, 463.

Conflict of Interest Statement: The author declares that the research was conducted in the absence of any commercial or financial relationships that could be construed as a potential conflict of interest.

Received: 18 March 2010; paper pending published: 29 March 2010; accepted: 08 April 2010; published online: 18 May 2010

Citation: Saura CA (2010) Presenilin $/ \gamma-\mathrm{sec}$ retase and inflammation. Front. Ag. Neuro sci. 2:16. doi: 10.3389/fnagi.2010.00016 Copyright (c) 2010 Saura. This is an openaccess article subject to an exclusive license agreement between the authors and the Frontiers Research Foundation, which permits unrestricted use, distribution, and reproduction in any medium, provided the original authors and source are credited. 